\title{
EFFICIENCY OF PUBLIC AND NONPUBLIC PRIMARY HEALTH CARE PROVIDERS IN POLAND
}

\section{ANNA LACHOWSKA}

\begin{abstract}
A B S T R A C T
The main aim of the paper is to reveal the outcomes of a research based on the efficiency of primary health care providers. The scientific goal of the mentioned research was the development of an efficiency measurement model and verification of its usefulness in practice. Overall, the research found that it is possible to use the efficiency measurement model for health care providers. Besides, significant differences were discovered in the efficiency of public and nonpublic primary health care providers. The research was conducted in the West Pomeranian Voivodship in Poland. This paper contributes to the widespread debate on public and nonpublic ownership in the field of healthcare. Also, it has practical implications as the research findings may be useful for any healthcare sector stakeholder, from decision makers to patients. The research was based on the literature overview, which allowed to elaborate the efficiency measurement model. The empirical research (based on a form of questionnaires) allowed testing the proposed model. The described efforts allowed drawing conclusions on the efficiency of primary health care institutions in the West Pomeranian Voivodship. The following methods of data analysis are presented in the paper: synthetic measure of development (SMD), Ward's method, and k-means method. According to the main conclusion of the research, it is possible to measure the efficiency of public and nonpublic health care providers of the Polish healthcare system. The proposed model for measuring the socioeconomic efficiency may be used as one of the tools used to measure the efficiency in the primary care. The verification of the usefulness of the model showed that nonpublic health care providers operating in the field of the public sector, outperformed public providers. The paper contributes to the theoretical field as it reveals a comprehensive approach to the efficiency measurement in the health care sector. The efficiency measurement model is based on the three major pillars of the healthcare sector, namely, income/resources, cost, and the social aspect. The elaborated efficiency measurement model for the healthcare sector was implemented and tested on a group of primary health care providers in the West Pomeranian Voivodship. The research allowed for positive conclusions regarding its usefulness in practice.
\end{abstract}

KEY WORDS

public, nonpublic, healthcare providers, efficiency

DOI: 10.1515/emj-2017-0014 pages: $57-63$
Corresponding author:

Anna Lachowska

The West Pomeranian Business School in Szczecin, Faculty of Economics and IT, Department of Economics, Poland e-mail: alachowska@zpsb.pl

\section{INTRODUCTION}

One of the key areas of the state protectionism in Poland is the healthcare. It is reflected in the Polish Constitution, which guarantees citizens equal access to health care services. However, in order to improve the efficiency of use of limited public funds, some market mechanism have been implemented.
In Poland, the first significant regulation imposed on the supply side of the market of medical services was the act on health care institutions of 1991 (Ustawa..., 1991). An important provision of the mentioned act was the implementation of public providers' independence and the introduction of the possibility for nonpublic entities to provide medical services in the public system. 
The growing debt of public health care providers, difficulties in the access to health services and the growing dissatisfaction of patients, indicate the need for restructuring of the Polish healthcare system. One of the most important issues is the improvement of the efficiency of public health care institutions by changing their legal structure. As perceived by the author, the need for research efforts in this area was justified by the lack of comparative studies on the economic and social efficiencies of the functioning of public and private providers in the publicly financed system.

\section{LITERATURE REVIEW}

Healthcare efficiency is a complex issue. On the one hand, the issue of the economic and social efficiencies should be defined separately. It is a common perception that the economic efficiency and the social efficiency remain antagonistic to each other. This is because the fulfilment of economic demands often precludes the fulfilment of social demands and vice versa. On the other hand, the characteristics of goods and services in the healthcare sector, as well as their importance, do not allow for the isolation of the economic and social efficiencies (Lachowska, 2014, p. 108). The healthcare system is a specific case, in which economic and social efficiencies are strongly interdependent (Stiglitz, 2004, p. 112). This translates into some disharmony of the existing healthcare systems (Lachowska, 2014, p. 108). The problem of the efficiency analysis lies in the field of the interest of whole organisations like WHO (WHO, 2000) or OECD (OECD, 2010) as well as many domestic and foreign researchers. Referring to the Polish praxeology, efficiency issues were considered by Kotarbiński (Kotrabiński, 1999, p. 324), Zieleniewski (Zieleniewski, 1969, p. 232), and Kieżun (Kieżun, 1978, p. 7). The efficiency analysis was studied by many foreign scholars, including Pareto (Morris et al., 2012, pp. 246-255), Koopmans (Koopmans, 1951, pp. 455-465), Debreu (Debreu, 1951, pp. 273-292), Leibenstein (Leibenstein, 1966, pp. 392415), Farrel (Farrel, 1957, pp. 253-290), and Charnes, Cooper and Rhodes (Charnes, Cooper \& Rhodes, 1978, pp. 429-444) who developed the field of production efficiency. Based on their findings, different efficiency analysis tools were developed, such as parametric (stochastic frontier analysis SFA) and nonparametric (data envelopment analysis DEA) methods. The mentioned efficiency analysis methods are applicable in the field of healthcare (Jacobs et al., 2006), although they have their constraints, e.g. omitting social issues. Referring to the query on the efficiency literature by Hollingsworth, the most popular is the DEA method, which is used by most hospitals (Hollingsworth, 2003, pp. 203-218). In the economic analysis of health care efficiency, different cost-related methods are proposed to be used, such as the costbenefit analysis, cost-utility analysis or cost-efficiency analysis (Folland et al., 2013, pp. 63-84). However, due to the difficulties in the value of human life and health assessment, the more useful is the cost-efficiency analysis (Garber \& Phelps, 1997, pp. 1-31).

So far, there has been no complex research showing the kind of efficiency methods commonly used in the Polish healthcare system; however, it might be assumed that the most popular are indicator methods, due to their usefulness and easiness of application. It may refer especially to smaller primary care providers. Domestic studies on the efficiency of health care institutions haven't focused so far on the distinction between the efficiency of public and nonpublic providers, which is a significant research gap.

\section{RESEARCH METHODS}

The literature overview has allowed elaborating the model for measuring the socioeconomic efficiency of health care institutions, which was tested during empirical studies. The mentioned model (Tab. 1) measures the efficiency in the three pillars of

Tab. 1. Model of measuring the economic and social efficiency of health care providers

\begin{tabular}{|l|l|l|}
\hline \multicolumn{2}{|c|}{ THREE - PILLARS OF THE EFFICIENCY MEASUREMENT SYSTEM } \\
\hline \multicolumn{1}{|c|}{$\begin{array}{c}\text { PILLAR I } \\
\text { INCOME/RESOURCES }\end{array}$} & \multicolumn{1}{|c|}{$\begin{array}{c}\text { PILLAR II } \\
\text { COSTS }\end{array}$} & \multicolumn{1}{c|}{$\begin{array}{c}\text { PILLAR III } \\
\text { SoCIAL ASPECT }\end{array}$} \\
\hline $\begin{array}{l}\text { Area of analysis: } \\
\text { the level of system's resource } \\
\text { absorption }\end{array}$ & $\begin{array}{l}\text { Area of analysis: } \\
\text { the real cost of services }\end{array}$ & $\begin{array}{l}\text { Area of analysis: } \\
\text { the ability to sustain and } \\
\text { improving health }\end{array}$ \\
\hline
\end{tabular}

Source: created by the author (Lachowska, 2014, p. 122). 
the healthcare system, according to designed efficiency indicators (Lachowska, 2014).

According to the model, the designed indicators were grouped into three groups referring to each pillar:

- income/resources pillar (the ratio of income to the number of cured patients $-\mathrm{Z} 1$, the ratio of income to the number of employees $-\mathrm{Z} 2$, the ratio of income to the amount of provided services $-\mathrm{Z} 3$, and the ratio of income to the average monthly size of patient population - Z4),

- cost pillar (the ratio of total costs to the number of cured patients $-\mathrm{K}$, the ratio of total costs to the number of employees - K2, the ratio of total costs to the amount of provided services $-\mathrm{K} 3$, and the total costs to income ratio - K4),

- social pillar (the ratio of provided services to the number of cured patients - S1, the ratio of patients that quit the institution to the average monthly size of patient population - S2, the ratio of total costs of diagnostic tests for patients to the total income - S3, and the ratio of the number of cured patients to the number of employees - S4).

The main criterion of the study was the form of ownership. The study involved providers with a public and nonpublic form of ownership. Additionally, the following criteria were taken into consideration:

- the type of activity - primary health care,

- a contract within the same branch of the National Health Fund.

The research involved the following stages:

- Stage 1: Literature overview, referring to the health care efficiency. Defining the efficiency and methods of its measurement;

- Stage 2: Primary research - collecting data from health care providers;

- Stage 3: Systematisation, control and processing of the research data;

- Stage 4: Analysis of efficiency indicators related to the proposed efficiency measurement model;

- Stage 5: Synthesis - drawing conclusions on the basis of the literature overview and empirical studies.

The research material was collected on the basis of a full survey conducted among the providers that meet the research criteria listed above. Respondents were asked to fill in the data questionnaire. The mentioned data were used to calculate the efficiency indicators according to the proposed model. Finally, the study involved 31 out of 297 primary health care providers operating under a contract with the National Health Fund in the West Pomeranian Voivodship. The group of public providers consists of eight entities, and the group of nonpublic providers has 23 entities. The calculated indicators were used to assess the efficiency of public and nonpublic providers according to the elaborated efficiency measurement model in the indicated three pillars of the health care system. As it was already mentioned, the article shows taxonomic methods of data analysis. The study covered the period 2009-2010, allowing for the verification of the usefulness of the model.

\section{RESEARCH RESULTS}

The analysis of the study results was made on the basis of several carefully selected statistical methods, which allowed drawing comprehensive conclusions of the research. The gathered data were also interpreted on the basis of taxonomic analysis methods. This analysis is used in a hierarchy of objects described in the multidimensional space of features, from the point of view of certain characteristics, in the case where it is impossible to measure it directly. The author selected the following methods: synthetic measure of development (SMD), Ward's method, and $\mathrm{k}$-means method.

The application of the first synthetic measure of development (SMD) showed that in terms of the used efficiency indicators, public health care providers were classified as the worst (Fig. 1 and 2) both in 2009 and 2010. As normalised synthetic measure of development ranges from 0 to 1 , where the highest value indicates higher efficiency according to the proposed efficiency indicators.

Normalised value of the synthetic measure of development for the highest classified nonpublic health care provider was 0.6447 in 2009 and 0.6309 in 2010. For the highest quoted public health care provider in 2009, the SMD value was 0.0759 and amounted to 0.0663 a year later.

In 2009, the average value of the indicator for nonpublic providers was 0.35 and in the case of public institutions - 0.03. In 2010, the average value of the indicator for nonpublic establishments decreased to 0.32 , and in the case of public providers, remained at 0.03 . A higher value of the normalised SMD indicates a higher the level of provider's efficiency referring to the proposed efficiency indicators. It is worth noticing that nonpublic providers have shown a significantly higher efficiency. 


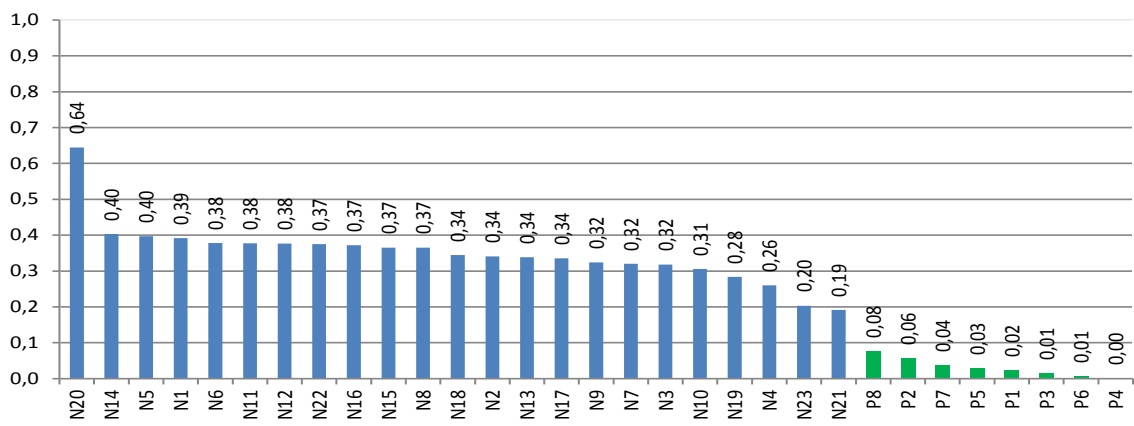

Fig. 1. Prioritising public and private health care institutions in terms of effectiveness in 2009, using SMD (where public providers are marked as "Pi", $\mathrm{i}=1-8$, while nonpublic providers as " $\mathrm{Nj}$ ", $\mathrm{j}=1-23$ )

Source: author's elaboration on the basis of own research (Lachowska, 2014, p. 168).

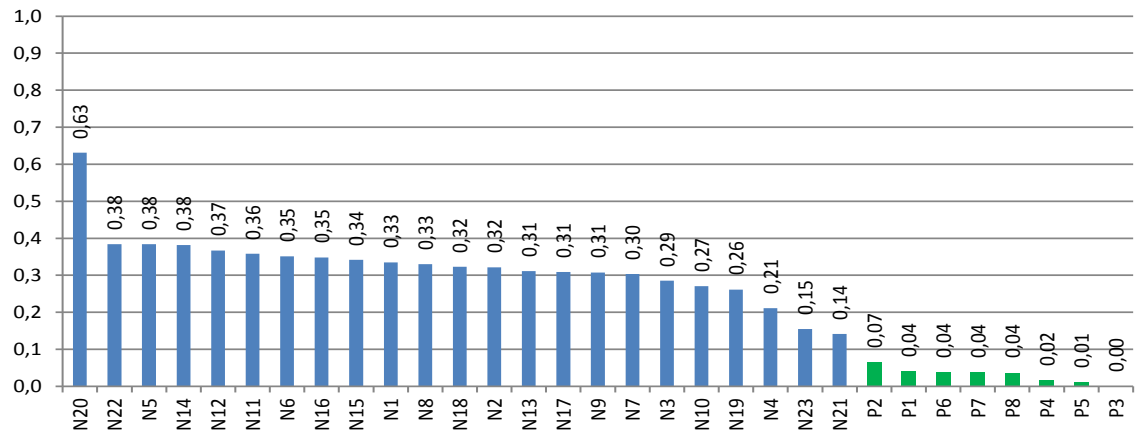

Fig. 2. Prioritising public and private health care institutions in terms of effectiveness in 2010, using SMD (where public providers are marked as "Pi", i = 1-8, while nonpublic providers as " $\mathrm{Nj",} \mathrm{j}=1-23$ ) Source: author's elaboration on the basis of own research (Lachowska, 2014, p. 168).

The average value of normalised SMD shows that measured by the proposed indicators in the research period, public health care providers showed the efficiency, which was more than ten times lower than that of nonpublic providers. The application of this method raises, therefore, an issue regarding the legitimacy of its use for a particular selection of indicators to measure the efficiency. The reflected differences in the efficiency of the test subjects should be verified using other statistical methods. For this purpose, the Ward method in combination with the k-means method may be used.

The implementation of the Ward method showed three

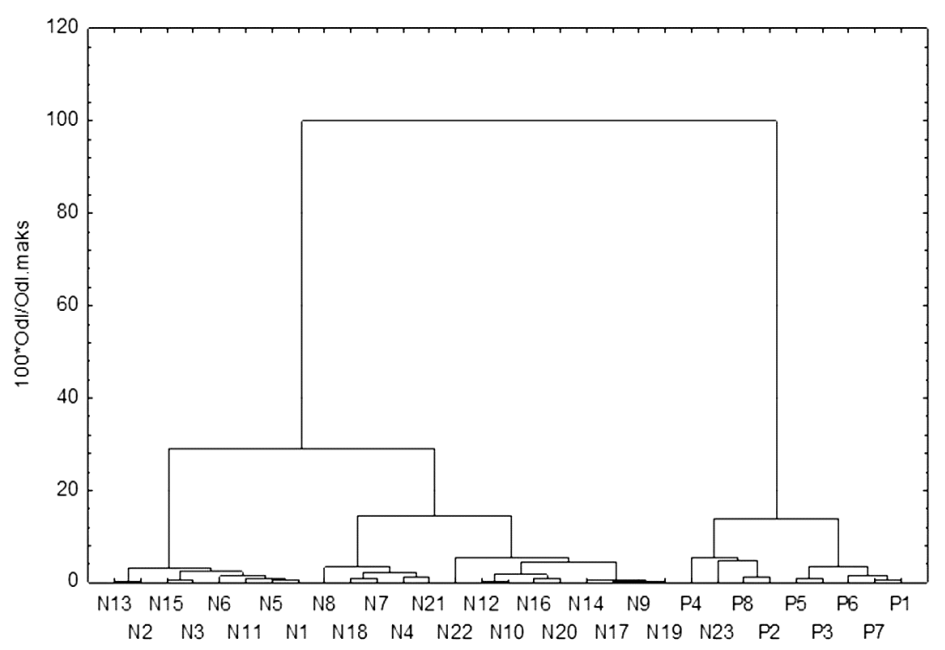

Fig. 3. Ward's dendrogram of health care providers in 2009 (where public providers are marked as "Pi", $\mathrm{i}=1-8$, while nonpublic providers as "Nj", $\mathrm{j}=1-23$ )

Source: author's elaboration on the basis of own research (Lachowska, 2014, p. 169). 


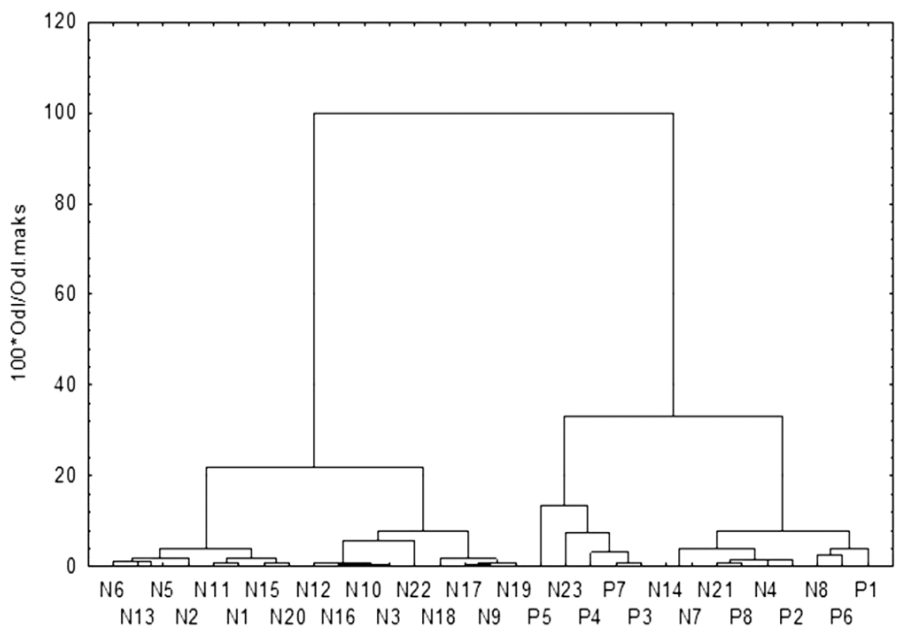

Fig. 4. Ward's dendrogram of health care providers in 2010 (where public providers are marked as "Pi", i = 1-8, while nonpublic providers as "Nj", j = 1-23)

Source: author's elaboration on the basis of own research (Lachowska, 2014, p. 170). providers showed that in 2009 , one group of public entities had the least favourable arrangement of these indicators (Group 3). In this group, there was also one nonpublic provider. Group 1 had the most favourable arrangement of the indicators and consisted of exclusively nonpublic providers. The average rates for groups of a similar level of efficiency in 2009 are shown in Tab. 2.

In 2010, this division was not as sharp because public providers were scattered in two groups (Fig. 6). The examination of the average values of the indicators in each of the newly formed groups showed that some public institutions, assigned to the most vulnerable groups in terms of efficiency indicators in 2009, groups of providers characterised by a similar level of efficiency. The tree diagram (Fig. 3) shows that in 2009, almost all of the examined public providers massed into a separate group, characterised by a similar level of efficiency referring to the proposed indicators.

In 2010, the distinction between public and non-public providers was not as sharp as the year before (Fig. 4).

Grouping of healthcare providers with the help of the k-means method has confirmed that in terms of the efficiency in 2009, public health care providers constituted a separate group of surveyed entities. Fig. 5 shows the grouping of the providers with a similar level of efficiency.

The examination of the average values of the indicators of individual groups of

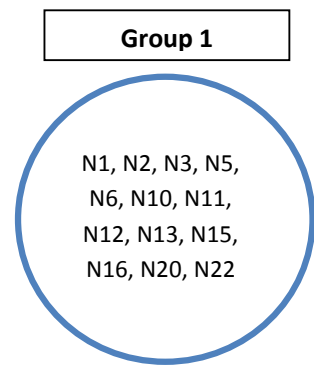

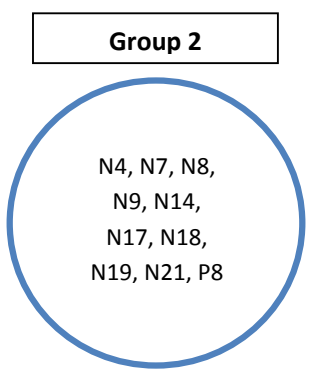

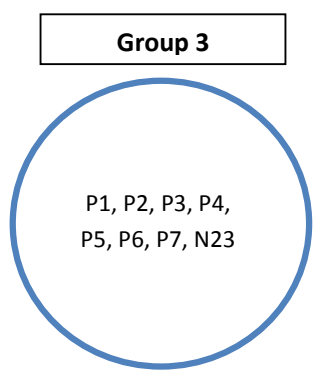

Fig. 5. Group of entities with a similar level of efficiency in 2009 (where public providers are marked as "Pi", i = 1-8, while nonpublic providers as "Nj", j = 1-23)

Source: author's elaboration on the basis of own research (Lachowska, 2014, p. 170).
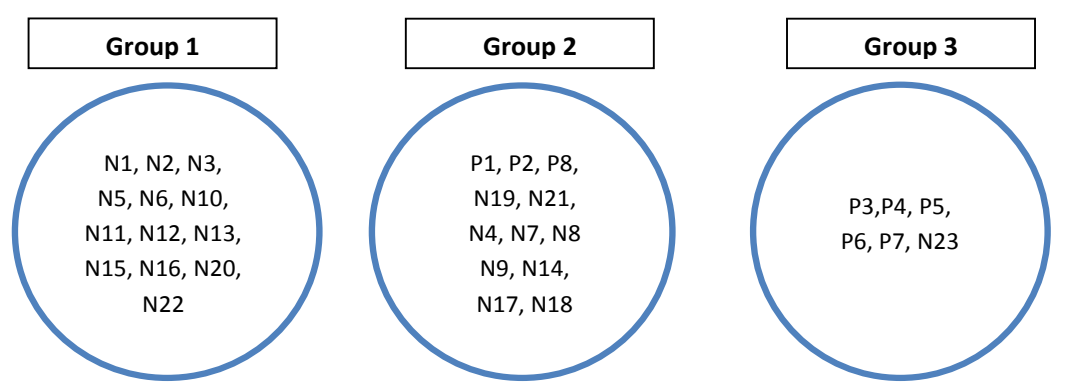

Fig. 6. Group of entities with a similar level of efficiency in 2010 (where public providers are marked as "Pi", i = 1-8, while nonpublic providers as "Nj", j = 1-23)

Source: author's elaboration on the basis of own research (Lachowska, 2014, p. 172). 
Tab. 2. Average rates for groups of providers of a similar level of efficiency in 2009

\begin{tabular}{|c|c|c|c|c|}
\hline \multirow{2}{*}{ INDICATORS } & \multirow{2}{*}{ UNIT OF MEASURE } & \multicolumn{3}{|c|}{ AVERAGE FOR INDICATOR } \\
\hline & & GROUP 1 & GROUP 2 & GROUP 3 \\
\hline $\mathrm{Z1}$ & (PLN/person) & 53.56 & 66.04 & 140.9 \\
\hline $\mathrm{Z2}$ & (PLN/employee) & 85116.90 & 102829.60 & 122996.2 \\
\hline $\mathrm{Z3}$ & (PLN/service) & 25.83 & 34.29 & 67.8 \\
\hline $\mathrm{Z4}$ & (PLN/person) & 4.93 & 5.05 & 5.4 \\
\hline K1 & (PLN/person) & 37.41 & 47.23 & 127.1 \\
\hline K2 & (PLN/employee) & 59819.63 & 75044.27 & 109028.6 \\
\hline K3 & (PLN/service) & 17.85 & 24.57 & 61.0 \\
\hline K4 & (percent) & 70.45 & 71.29 & 88.9 \\
\hline S1 & (PLN/service) & 2.11 & 1.92 & 2.1 \\
\hline S2 & (percent) & 0.86 & 1.20 & 3.4 \\
\hline S3 & (percent) & 12.26 & 9.75 & 3.7 \\
\hline S4 & (person/employee) & 1748.92 & 1728.51 & 959.9 \\
\hline
\end{tabular}

Source: author's elaboration on the basis of own research (Lachowska, 2014, p. 171).

Tab. 3. Average rates for groups of providers of a similar level of efficiency in 2010

\begin{tabular}{|c|c|c|c|c|}
\hline \multirow{2}{*}{ INDICATORS } & \multirow{2}{*}{ UNIT OF MEASURE } & \multicolumn{3}{|c|}{ AVERAGE FOR INDICATOR } \\
\hline & & GROUP 1 & Group 2 & Group 3 \\
\hline $\mathrm{Z1}$ & (PLN/person) & 52.84 & 80.5 & 123.33 \\
\hline $\mathrm{Z2}$ & (PLN/employee) & 85097.50 & 104985.2 & 124121.20 \\
\hline $\mathrm{Z3}$ & (PLN/service) & 25.81 & 38.7 & 62.30 \\
\hline $\mathrm{Z4}$ & (PLN/person) & 4.92 & 5.1 & 5.03 \\
\hline K1 & (PLN/person) & 37.70 & 62.0 & 114.65 \\
\hline $\mathrm{K} 2$ & (PLN/employee) & 61101.30 & 79787.3 & 112723.00 \\
\hline K3 & (PLN/service) & 18.42 & 29.8 & 57.52 \\
\hline K4 & (percent) & 71.99 & 75.3 & 91.06 \\
\hline S1 & (PLN/service) & 2.07 & 2.0 & 1.95 \\
\hline $\mathrm{S} 2$ & (percent) & 0.90 & 1.6 & 2.72 \\
\hline S3 & (percent) & 12.62 & 8.6 & 4.16 \\
\hline S4 & (person/employee) & 1726.25 & 1524.7 & 1128.39 \\
\hline
\end{tabular}

Source: author's elaboration on the basis of own research (Lachowska, 2014, p. 172).

law that introduced the obligation to pay out the debt of public institutions by its founding body. This likely contributed to the increased control over the activities of public institutions, which could have led to the improvement of their efficiency.
In summary, the carried out analysis using the Ward's and k-means methods showed that there was a clear distinction between public and private health care providers in terms of the efficiency in 2009. In the study period 2009-2010, there were no public 
providers in the first group that had the most advantageous arrangement of indicators in both years.

\section{DISCUSSION OF THE RESULTS}

The presented research has its practical and theoretical implications. The literature overview allows making conclusions regarding the Polish healthcare system, one of which indicates that the system is not working properly. One of the most significant causes of the existing situation is a defective legal solution in the field of public health care providers. Poland still has insufficient research on the efficiency of public and nonpublic providers operating on the basis of public funds. It translates into certain analytical and decisive frailty of the healthcare system authorities. Foreign studies do not suggest conclusions in this respect. However, it is possible to measure the efficiency of health care providers in Poland using appropriately constructed and adapted measurement tools, such as the presented model of economic and social efficiencies of health care institutions. The conducted research has shown that in the period 2009-2010, nonpublic providers operating in the public field in the West Pomeranian Voivodship were far more efficient than public providers. The majority of public entities have noticed a worse efficiency level according to the model proposed for the measurement of economic and social efficiencies (using a different taxonomic method of analysis). Taking into consideration the size of the surveyed population and the research period, conclusions on the entire Polish population are constrained. However, the verification of the usefulness of the model allows implementing it into the practice, which enables the continuation of the research in the future. It should also be mentioned that the defective legal system is one of the factors influencing on the efficiency of health care providers. The problem the efficiency of public and nonpublic provider is more complex and requires further research and analysis of the differences in the public and nonpublic parts of the healthcare sector.

\section{LITERATURE}

Charnes, A., Cooper, W. W., \& Rhodes, E. (1978). Measuring the efficiency of decision making units. European Journal of Operational Research, 2(6), 429-444.
Debreu, G. (1951). The coefficient of resource utilization. Econometrica, 19(3), 273-292.

Farrell, M. J. (1957). The measurement of Productive Efficiency. Journal of the Royal Statistical Society, 120(3), 253-290.

Folland, S., Goodmand, A. C., \& Stano, M. (2013). The Economics of Health and Healthcare. New Yersey, USA: Pearson Education.

Garber, A. M., \& Phelps, C. E. (1997). Economic Foundations of Cost - Effectiveness Analysis. Journal of Health Economics, 16(1), 1-31.

Hollingsworth, B. (2003). Non-parametric and parametric applications measuring efficiency in health care. Health care management and Science, 6(4), 203-218.

Jacobs, R., Smith, P. C., \& Street, A. (2006). Measuring efficiency in health care: Analytic techniques and health policy. Cambridge, England: Cambridge University Press.

Kotarbiński, T. (1999). Prakseologia, część I [Praxeology, part I]. Wrocław, Poland: Zakład Narodowy im. Ossolińskich.

Kieżun, W. (1978). Ewolucja sprawnego zarządzania [Evolution of efficient management]. Warszawa, Poland: Państwowe Wydawnictwo Ekonomiczne.

Leibenstein, H. (1966). Allocative efficiency vs X efficiency. The American Economic Review, 3(56), 394-415.

Koopmans, T. C. (1951). Efficient allocation of resources. Econometrica, 19(4), 455-465.

Lachowska, A. (2014). Efektywność funkcjonowania publicznych i niepublicznych zakładów opieki zdrowotnej $w$ województwie zachodniopomorskim [Efficiency of public and nonpublic health care providers in the West Pomeranian Voivodship] [not published PhD thesis].

Morris, S., Devlin, N., \& Parkin, D. (2012). Economic Analysis in Healthcare. Chichester, England: John Wiley \& Sons Ltd.

Organisation for Economic Co-operation and Development. (2010). Health Care Systems: efficiency and Policy Settings. Retrieved from http://www.oecd.org/ eco/healthcaresystemsefficiencyandpolicysettings. htm

Ustawa z dnia 30 sierpnia 1991r. o zakładach opieki zdrowotnej [The act of 30 August 1991 about healthcare facilities] (Dz.U. 1991, nr 91, poz. 408) 1991 (PL).

World Health Organization. (2000). World Health Report 2000. Retrieved from http://www.who.int/whr/2000/ en/whr00_en.pdf

Zieleniewski, J. (1969). Organizacja i zarządzanie [Organization and management]. Warszawa, Poland: PWN. 